\title{
Relationship of urinary isoprostanes to prostate cancer occurence
}

\author{
Magdalena Brys • Agnieszka Morel • \\ Ewa Forma • Anna Krzeslak • Jacek Wilkosz • \\ Waldemar Rozanski • Beata Olas
}

Received: 7 June 2012/ Accepted: 5 September 2012/Published online: 16 September 2012

(c) The Author(s) 2012. This article is published with open access at Springerlink.com

\begin{abstract}
To estimate the oxidative stress in patients with prostate cancer and in a control group, we used the biomarker of lipid peroxidation-isoprostanes $\left(8-\mathrm{isoPGF}_{2}\right)$ and the level of selected antioxidants (glucose and uric acid [UA]). The level of urinary isoprostanes was determined in patients and controls using an immunoassay kit according to the manufacturer's instruction. The levels of UA and glucose were also determined in serum by the use of UA Assay Kit and Glucose Assay Kit. We observed a statistically increased the level of isoprostanes in urine of patients with prostate cancer in compared with a control group. The concentration of tested antioxidants in blood from patients with prostate cancer was also higher than in healthy subjects. Moreover, our experiments indicate that the correlation between the increased amount of UA and the lipid peroxidation exists in prostate cancer patients (in all tested groups). Prostate cancer risk by urinary isoprostanes level was analyzed, and a positive association was found (relative risk for highest vs. lowest quartile of urinary isoprostanes $=1.6 ; 95 \%$ confidence interval $1.2-2.4 ; p$ for trend $=0.03)$. We suggest that reactive oxygen species induce peroxidation of unsaturated fatty acid in patients
\end{abstract}

M. Brys · E. Forma · A. Krzeslak

Department of Cytobiochemistry, Faculty of Biology and Environmental Protection, University of Lodz, Pomorska 141/143, 90-236 Lodz, Poland

A. Morel · B. Olas $(\bowtie)$

Department of General Biochemistry, Institute of Biochemistry, Faculty of Biology and Environmental Protection,

University of Lodz, Pomorska 141/143, 90-236 Lodz, Poland

e-mail: olasb@biol.uni.lodz.pl

J. Wilkosz · W. Rozanski

2nd Department of Urology, Medical University of Lodz,

Pabianicka 62, 93-513 Lodz, Poland with prostate cancer, and the level of isoprostanes may be used as a non-invasive marker for determination of oxidative stress. We also propose that UA may enhance the oxidative stress in patients with prostate cancer.

Keywords Isoprostanes - Prostate cancer - Oxidative stress · Uric acid

\section{Introduction}

In different disorders, including cancer, oxidative stress is observed [1]. Oxidative stress leads to lipid peroxidation and may contribute to the pathogenesis of lesions in cancer, including prostate cancer [2], however, the mechanism of prostate carcinogenesis is not completely understood. In the presence of reactive oxygen species, double bonds of unsaturated fatty acids of phospholipids are oxidized. A scission of the oxidized polyunsaturated fatty acids results in the formation of phospholipid aldehydes such as oxidized phosphatidylcholine and aldehyde cleavage fragments including malonyldialdehyde, 4-hydroxynonenal, and acrolein [3]. Reactive oxygen species catalyzed peroxidation of arachidonic acid esterified in membrane phospholipids also leads to the formation of isoprostanes, which are prostaglandin-like compounds [4-9]. Oxidative stress may be determined by special biomarkers-the level of lipid hydroperoxides, conjugated dienes, thiobarbituric acid reactive substances, and reactive oxygen species.

The measurements of lipid peroxidation products in vitro relies on indirect methods. The specific and reliable markers of lipid peroxidation in vivo seem to be isoprostanes [5-7, 10-12], therefore, the aim of our study was to determine the level of urinary excretion of 8-isoprostaglandin $\mathrm{F}_{2}$ (8-iso$\mathrm{PGF}_{2 \alpha}$ ) in patients with prostate cancer and in healthy 
subjects, and also to estimate oxidative stress in patient groups and a control group on the basis of antioxidants (glucose and uric acid [UA]) in blood. However, recent studies suggest that UA can become a prooxidant $[13,14]$.

\section{Materials and methods}

Patients and samples

The blood and urine samples were collected from 304 patients who had been referred to the 2nd Clinic of Urology, Department of Urology, Medical University of Łódź, Poland, between February 2009 and January 2012.

Blood was collected into sodium citrate $(5 \mathrm{mM}$ final concentration). Blood $(9 \mathrm{ml})$ was drawn between 8 a.m. and 8.30 a.m. and sampled from an antecubital vein. For each subject, we recorded blood platelet counts, red blood, white blood cell counts, and the level of selected antioxidants (in serum), as well as the medical history and medications used. A urine sample was also collected between 8 a.m. and 8.30 a.m. and immediately stored at $-70{ }^{\circ} \mathrm{C}$. The urine samples were collected from patients prior to prostate biopsy. The number of collection (for blood and urine) was one per patient. Demographic data and medical history were obtained at the entry of each patient to the study (Table 1). The final diagnosis of prostate cancer was based on

Table 1 Demographic and clinical characteristics of study subjects

\begin{tabular}{|c|c|c|}
\hline & Prostate cancer $(\%)$ & Controls $(\%)$ \\
\hline Sample size & $n=304$ & $n=233$ \\
\hline Age, years & $61.4 \pm 9.26$ & $65.2 \pm 13.1$ \\
\hline \multicolumn{3}{|l|}{ Serum PSA $(\mathrm{ng} / \mathrm{ml})^{\mathrm{a}}$} \\
\hline$<4$ & $15(4.9)$ & $155(66.5)$ \\
\hline$\geq 4-10$ & $36(12.0)$ & $78(33.5)$ \\
\hline$\geq 10-100$ & $215(70.7)$ & 0 \\
\hline$>100$ & $38(12.4)$ & 0 \\
\hline \multicolumn{3}{|l|}{ Gleason score } \\
\hline $2-4$ (group I) & $100(33.0)$ & 0 \\
\hline 5-7 (group II) & $155(51.0)$ & 0 \\
\hline 8-10 (group III) & $49(16.0)$ & 0 \\
\hline \multicolumn{3}{|l|}{ Stage } \\
\hline T1-2N0M0 & $124(41.0)$ & 0 \\
\hline T3-4N0M0 & $82(27.0)$ & 0 \\
\hline TxN1 or M1 & $98(32.0)$ & 0 \\
\hline \multicolumn{3}{|l|}{ Prostate volume } \\
\hline$<30 \mathrm{ml}$ & $97(32.0)$ & $84(36.0)$ \\
\hline 30 to $50 \mathrm{ml}$ & $124(41.0)$ & $91(39.0)$ \\
\hline$\geq 50 \mathrm{ml}$ & $83(27.0)$ & $58(25.0)$ \\
\hline
\end{tabular}

a PSA (prostate specific antigen) as measured at the time of diagnosis histopathologic examination. Patients diagnosed with previous prostate tumors or with tumors located elsewhere were excluded. None of the recruited patients received preoperative chemo- or radiotherapy. A group of 233 healthy individuals were collected from the hospital from routine controls of health and used as control. They were non-related men, who have never been diagnosed with prostate tumors, other tumors, or chronic disease, and were randomly selected and frequency matched to the cases on age. The urine and blood samples were taken from patients or healthy subjects not taking any medications or addictive substances (including tobacco or alcohol), keeping a balanced diet (meat and vegetables), with similar socio-economic background, using no antioxidant supplementation. Cases were divided into three groups according to the histologic grade. Group Igleason scores 2-4, group II-gleason scores 5-7, and group III-gleason scores 8-10. The volume of the prostate was calculated using the standard ellipsoid formula, width $\times$ height $\times$ length $\times \pi / 6$.

The protocol was passed by the Committee for Research on Human Subjects of the Medical University of Lodz No. RNN/59/09/KE.

\section{Measurement of PSA}

The serum total PSA level was assayed by immunometric analysis using the Abbott IMx Total PSA assay kit (Abbott Laboratories).

\section{Measurement of lipid peroxidation}

The level of 8 -isoPGF ${ }_{2 \alpha}$ was estimated in urine samples from control subjects and from patients using non-specific immunoassay kit (Oxis International, Inc.) according to the manufacturer's instructions.

Measurement of uric acid and glucose levels

The levels of UA and glucose were determined in serum by the use of Uric Acid Assay Kit and Glucose Assay Kit (all Abcam, Cambridge, UK), respectively, according to the manufacturer's protocol.

Statistical analysis

The statistical analysis was done by several tests. All values in this study were expressed as mean $\pm \mathrm{SD}$. In order to eliminate uncertain data, the Q-Dixon test was performed. The statistically significant difference between the control group and patients was done by Mann-Whitney test. We used Cox regression analysis to assess the association of urinary isoprostanes with the risk of prostate cancer. Reported $p$ values were two-sided. Probabilities were 
considered significant whenever $p$ value was lower than 0.05. All analyzes were completed using STATA software (version 11.0 StataCorp., Texas, USA).

\section{Results}

Our studies showed that the level of 8 -isoPGF $2 \alpha$ in urine from patients with prostate cancer was markedly higher than the level of 8-isoPGF $2 \alpha$ in the control healthy subjects (Table 2). In control group, the level of 8 -isoPGF $2 \alpha$ in urine was $259.4 \pm 39.4 \mathrm{pg} / \mathrm{mg}$ of creatinine, whereas samples of patients with prostate cancer (gleason scores 2-4) contained $437.2 \pm 112.4 \mathrm{pg}$ of 8 -isoPGF $2 \alpha / \mathrm{mg}$ of creatinine. We also observed a statistically increased level of 8 -isoPGF $2 \alpha$ in urine of patients with prostate cancer belonging to groups II and III in compared with a control group (Table 2). Moreover, the concentration of tested biomarker in urine from patients with more anaplastic prostate cancer (group III) was higher than in patients with prostate cancer classified as gleason scores 2-4 and 5-7 (about 20\%-group I vs. group II; and about $200 \%$-group III vs. group I) (Table 2).

We observed higher level of UA and glucose in serum of all prostate cancer patients (groups I, II, and III) than in control group (Table 2).

In this study, we did not find statistically significant correlation between concentrations of investigated compounds (8-isoPGF $2 \alpha, \mathrm{UA}$, and glucose) and patient's age (data not shown). The correlation between the increased amount of UA and changes in the level of 8 -isoPGF ${ }_{2 \alpha}$, in patients with prostate cancer (classified as groups I, II, and III [gleason score] and for stage classification) is presented in Table 3.

Table 4 shows relative risk of prostate cancer by quartile of serum isoprostanes. These analyzes were run with adjustment for age. We observed a significant positive trend in these data.

\section{Discussion}

Oxidation of polyunsaturated fatty acids changes the biological activity of phospholipids that is important for the integrity of cellular membranes. Two pathways of lipid peroxidation can occur: enzymatic and nonenzymatic. Free polyunsaturated fatty acids can be oxidized by multiple enzymes forming the reactive lipid mediators such as prostaglandins, thromboxanes, prostacyclins, lipoxins, and hepoxylins. Nonenzymatic lipid peroxidation process initiated by reactive oxygen species leads to the formation of different products, mainly isoprostanes, isothromboxanes, isolevuglandins, and isofuranes. Isoprostanes are the most important biomarkers of oxidative stress in human diseases [15-18]. In our study, isoprostanes were estimated in urine of prostate cancer patients and healthy volunteers. Measurement of 8 -isoPGF $2 \alpha$ in a single sample of urine represents daily secretion of
Table 2 The level of 8 -isoPGF ${ }_{2 \alpha}$ (the marker of lipid peroxidation) in urine and the level of selected antioxidants (glucose and UA) in serum from patients with prostate cancer, and in control urine and serum obtained from healthy volunteers

\begin{tabular}{|c|c|c|c|}
\hline & $\begin{array}{l}\text { Level of } 8 \text {-isoPGF } 2 \alpha \\
\text { (pg/mg creatinine) }\end{array}$ & $\begin{array}{l}\text { Level of glucose } \\
(\mathrm{mg} / \mathrm{dl})\end{array}$ & $\begin{array}{l}\text { Level of uric acid } \\
(\mathrm{mg} / \mathrm{dl})\end{array}$ \\
\hline Control, $n=233$ (A) & $259.4 \pm 39.4$ & $74.9 \pm 19.3$ & $3.5 \pm 1.2$ \\
\hline \multicolumn{4}{|l|}{ Gleason score } \\
\hline Group I, $n=100$ (B) & $\begin{array}{l}437.2 \pm 112.4 \\
(\mathrm{~B} \text { vs. } \mathrm{A}, p<0.001)\end{array}$ & $\begin{array}{l}100.3 \pm 14.9 \\
(\mathrm{~B} \text { vs. } \mathrm{A}, p<0.001)\end{array}$ & $\begin{array}{l}5.6 \pm 3.0 \\
(\text { B vs. A, } p<0.01)\end{array}$ \\
\hline Group II, $n=155$ (C) & $\begin{array}{l}742.3 \pm 197.5 \\
(\mathrm{C} \text { vs. } \mathrm{A}, p<0.001 \\
\mathrm{C} \text { vs. } \mathrm{B}, p<0.001)\end{array}$ & $\begin{array}{l}105.7 \pm 29.7 \\
(\mathrm{C} \text { vs. } \mathrm{A}, p<0.001 \\
\mathrm{C} \text { vs. } \mathrm{B}, p>0.05)\end{array}$ & $\begin{array}{l}8.2 \pm 2.3 \\
(\mathrm{C} \text { vs. } \mathrm{A}, \mathrm{p}<0.001 \\
\quad \mathrm{C} \text { vs. } \mathrm{B}, p<0.001)\end{array}$ \\
\hline Group III, $n=49$ (D) & $\begin{array}{l}877.8 \pm 217.4 \\
(\mathrm{D} \text { vs. } \mathrm{A}, p<0.001 \\
\mathrm{D} \text { vs. } \mathrm{B}, p<0.001 \\
\text { D vs. } \mathrm{C}, p<0.01)\end{array}$ & $\begin{array}{l}110.6 \pm 33.4 \\
\text { (D vs. } \mathrm{A}, p<0.001 \\
\text { D vs. } \mathrm{B}, p>0.05 \\
\text { D vs. } \mathrm{C}, p>0.05 \text { ) }\end{array}$ & $\begin{array}{l}8.8 \pm 2.5 \\
\text { (D vs. } \mathrm{A}, p<0.001 \\
\text { D vs. } \mathrm{B}, p<0.001 \\
\text { D vs. } \mathrm{C}, p>0.05 \text { ) }\end{array}$ \\
\hline \multicolumn{4}{|l|}{ Stage classification } \\
\hline T1-2N0M0, $n=124(\mathrm{E})$ & $\begin{array}{l}570.4 \pm 82.5 \\
\text { (E vs. } \mathrm{E}, p<0.001)\end{array}$ & $\begin{array}{l}99.4 \pm 14.2 \\
(\mathrm{E} \text { vs. } \mathrm{E}, p<0.001)\end{array}$ & $\begin{array}{l}6.6 \pm 2.7 \\
(\mathrm{E} \text { vs. } \mathrm{E}, p<0.01)\end{array}$ \\
\hline T3-4N0M0, $n=82(\mathrm{~F})$ & $\begin{array}{l}927.1 \pm 281.4 \\
(\mathrm{~F} \text { vs. } \mathrm{A}, p<0.001 \\
\quad \text { F vs. } \mathrm{E}, p<0.001)\end{array}$ & $\begin{array}{l}111.3 \pm 30.4 \\
(\mathrm{~F} \text { vs. } \mathrm{A}, p<0.001 \\
\text { F vs. } \mathrm{E}, p<0.05)\end{array}$ & $\begin{array}{l}9.0 \pm 2.5 \\
(\mathrm{~F} \text { vs. } \mathrm{A}, p<0.001 \\
\quad \mathrm{F} \text { vs. } \mathrm{E}, p<0.001)\end{array}$ \\
\hline TxN1 or M1, $n=98(\mathrm{G})$ & $\begin{array}{l}935.3 \pm 254.6 \\
\text { (G vs. A, } p<0.001 \\
\text { G vs. } \mathrm{E}, p<0.001 \\
\text { G vs. } \mathrm{F}, p<0.05)\end{array}$ & $\begin{array}{l}113.7 \pm 29.5 \\
\text { (G vs. } \mathrm{A}, p<0.001 \\
\mathrm{G} \text { vs. } \mathrm{E}, p>0.05 \\
\mathrm{G} \text { vs. } \mathrm{F}, p>0.05)\end{array}$ & $\begin{array}{l}9.2 \pm 2.4 \\
(\mathrm{G} \text { vs. } \mathrm{A}, p<0.001 \\
\mathrm{G} \text { vs. } \mathrm{E}, p<0.001 \\
\mathrm{G} \text { vs. } \mathrm{F}, p>0.05)\end{array}$ \\
\hline
\end{tabular}

Results are mean \pm SD. The statistical analysis was done by Mann-Whitney test 
Table 3 The correlation between the selected parameters of oxidative stress-the level of 8 -isoPGF $2 \alpha$ and the level of UA (for classifications-gleason score and stage classification)

The correlation between the level of isoprostanes ( $\mathrm{pg} / \mathrm{mg}$ creatinine) and the level of uric acid $(\mathrm{mg} / \mathrm{dl})$

\begin{tabular}{|c|c|}
\hline $\begin{array}{l}\text { Gleason } \\
\text { classification: }\end{array}$ & \\
\hline Group I & $r=0.7781(p<0.001)$ \\
\hline Group II & $r=0.7653(p<0.001)$ \\
\hline Group III & $r=0.6194(p<0.001)$ \\
\hline & $\begin{array}{l}\text { The correlation between } \\
\text { (pg/mg creatinine) and } \\
(\mathrm{mg} / \mathrm{dl})\end{array}$ \\
\hline $\begin{array}{l}\text { Stage } \\
\text { classification: }\end{array}$ & \\
\hline T1-2N0M0 & $r=0.7234(p<0.001)$ \\
\hline T3-4N0M0 & $r=0.7008(p<0.001)$ \\
\hline TxN1 or M1 & $r=0.6056(p<0.001)$ \\
\hline
\end{tabular}

Table 4 Relative risk of prostate cancer by quartile of urinary isoprostanes

\begin{tabular}{lrll}
\hline $\begin{array}{l}\text { Quartile of isoprostanes } \\
(\mathrm{pg} / \mathrm{mg} \text { creatinine })\end{array}$ & $\begin{array}{l}\text { No. of } \\
\text { cases }(\%)\end{array}$ & $\begin{array}{l}\text { Relative risk } \\
(95 \% \mathrm{CI})\end{array}$ & $\begin{array}{l}P \text { for } \\
\text { trend }^{\mathrm{b}}\end{array}$ \\
\hline$\leq 342.3$ & $49(16.1)$ & 1.00 (reference) & \\
$342.4-684.5$ & $87(28.6)$ & $1.2(0.7-1.6)$ & \\
$684.6-1,026.8$ & $135(44.4)$ & $1.4(0.80-2.2)$ & \\
$\geq 1,026.9$ & $33(10.9)$ & $1.6(1.2-2.4)$ & 0.03
\end{tabular}

a Adjusted across two age categories: $40-59, \geq 60$ years

b Cochran-Armitage test for trend

CI confidence interval

isoprostanes, which are the end products of peroxidation of arachidonic acid. The source of 8 -isoPGF $2 \alpha$ may be oxidized arachidonic acid derived from different cells including neurons, blood platelets, and erythrocytes [5-7, 10-12].

This study, for the first time, provides evidence that patients with prostate cancer have extremely high level of urinary 8 -iso $\mathrm{PGF}_{2 \alpha}$ (measured by using a sensitive immunoassay). It indicates that the oxidative stress takes place. The obtained results are consistent with those in the literature [2]. Barocas et al. [2] measured (by gas chromatography/negative ion chemical ionization mass spectrometry) the urinary level of $\mathrm{F}_{2}$-isoprostane, and they observed a statistically significant trend in prostate cancer risk with increasing of $\mathrm{F}_{2}$-isoprostane level. They observed that $\mathrm{F}_{2}$-isoprostane level was higher not only in patients with prostate cancer, but also in patients with high-grade prostatic intraepithelial neoplasia.

The presence of various antioxidants (UA, glutathione, and glucose) in blood is responsible for the protection against the oxidative stress [19]. The most potent of them is UA. This final metabolite of purine catabolism is a biomarker of oxidative stress, but it can also act as a prooxidant $[13,14]$. The high level of glucose may also play a role of the inducer of oxidative stress [19]. In our study, the level of UA and glucose in serum was higher in patients with prostate cancer than in control. However, the levels of serum glucose among all tested groups of patients (for Gleason classification and stage classification) were the same. This study provides more information about mechanisms of oxidative stress in prostate cancer. The first time, our results showed that the elevated level of UA may play an important role in the oxidative stress in prostate cancer patients. Experiments presented here showed that there was a correlation between the increased amount of UA and the oxidative stress in patients with prostate cancer. It should be underlined that in our experiments, samples from patients were taken before surgery, and prostate cancer patients have not had preadjuvant therapy.

Our results support the hypothesis that oxidative stress (measured by various biomarkers, including lipid peroxidation) may play a role in prostate cancer. We also presented that in prostate cancer patients, the level of oxidative stress was not dependent on patient's age. However, further studies are needed to evaluate the impact of pharmacologic treatment on modification of lipids in prostate cancer. The next step of future studies is to evaluate the role of various compounds (antioxidants and prooxidants) in the oxidative stress in patients with prostate cancer.

Acknowledgments This study was supported by the Grant 506/810(KBO) from University of Lodz, Poland.

Open Access This article is distributed under the terms of the Creative Commons Attribution License which permits any use, distribution, and reproduction in any medium, provided the original author(s) and the source are credited.

\section{References}

1. Afanas'ev I (2011) Reactive oxygen species signaling in cancer: comparison with aging. Aging Dis 2:219-230

2. Barocas DA, Motley S, Cookson MS, Chang SS, Penson DFP, Dai Q, Milne G, Jackson L, Morrow RJ, Concepcion RS, Smith JA, Fowke JH (2011) Oxidative stress measured by urine F2isoprostane level is associated with prostate cancer. J Urol 185:2102-2107

3. Adighatla MR, Hatcher JF (2008) Altered lipid metabolism in brain injury disorders. Subcell Biochem 49:241-268

4. Morrow JD, Hill KE, Burk RF, Nammour TM, Badr KF, Roberts LJ II (1990) A series of prostaglandin $\mathrm{F}_{2}$-like compounds are produced in vivo in humans by a non-cyclooxygenase, free radical-catalyzed mechanism. Proc Natl Acad Sci USA 87:9383-9387

5. Cracowski JL, Durand T (2006) Cardiovascular pharmacology and physiology of the isoprostanes. Fundam Clin Pharmacol $20: 417-427$ 
6. Basu S (2004) Isoprostanes: novel bioactive products of lipid peroxidation. Free Radic Res 38:105-122

7. Davi G, Falco A, Patrono C (2004) Determination of $\mathrm{F}_{2}$-isoprostane biosynthesis and inhibition in man. Chem Phys Lipids 128:149-163

8. Roberts LJ, Morrow JD (2000) Measurement of $\mathrm{F}_{2}$-isoprostanes as an index of oxidative stress in vivo. Free Radic Biol Med 28:505-513

9. Roberts LJ, Fessel JP (2004) The biochemistry of the isoprostane, neuroprostane, and isofuran pathways of lipid peroxidation. Chem Phys Lipids 128:173-186

10. Fam SS, Morrow JD (2003) The isoprostanes: unique products of arachidonic acid oxidation. Curr Med Chem 10:1723

11. Hou X, Roberts LJ, Gobeil JF, Taber D, Kanai K, Abran D, Brault S, Checchin D, Sennlaub F, Lachapelle P, Varma D, Chemtob S (2004) Isomer specific contractile effects of a series of synthetic $\mathrm{F}_{2}$-isoprostanes on retinal and cerebral microvasculature. Free Radic Biol Med 6:163-172

12. Gao L, Yin H, Milne GL, Porter NA, Morrow JD (2006) Formation of F-ring isoprostane-like compounds ( $\mathrm{F}_{3}$-isoprostanes) in vivo from eicosapentaenoic acid. J Biol Chem 281:14092-14099

13. Kim KM, Henderson GN, Ouyang X, Frye RF, Sautin YY, Feig DI, Johnson RJ (2009) A sensitive and specific liquid chromatography-tandem mass spectrometry method for the determination of intracellular and extracellular uric acid. J Chromatogr B Anal Technol Biomed Life Sci 877:2032-2038

14. Sanguinetti SM, Batthyany C, Trostchansky A, Botti H, Lopez GI, Wikinski RL, Rubbo H, Schreier LE (2004) Nitric oxide inhibits prooxidant actions of uric acid during copper-mediated LDL oxidation. Arch Biochem Biophys 15:302-308

15. Lawson JA, Rokach J, Fitzgerald GA (1999) Isoprostanes: formation, analysis, and use as indices of lipid peroxidation in vivo. J Biol Chem 274:24441-24444

16. Montuschi P, Barnes P, Roberts JL (2004) Isoprostanes: markers and mediators of oxidative stress. The FOSEB J 18:1792-1796

17. Milne GL, Musiek ES, Morrow JD (2005) $F_{2}$-Isoprostanes: a marker of oxidative stress in vivo. Biomarkers 1:S10-S23

18. Milne GL, Yin H, Brooks JD, Sanchez S, Jackson RL, Morrow JD (2007) Quantification of $F_{2}$-isoprostanes in biological fluids and tissues as a measure of oxidant stress. Methods Enzymol 433:113-126

19. Young IS, Woodside JY (2001) Antioxidants in health and disease. J Clin Pathol 54:176-186 